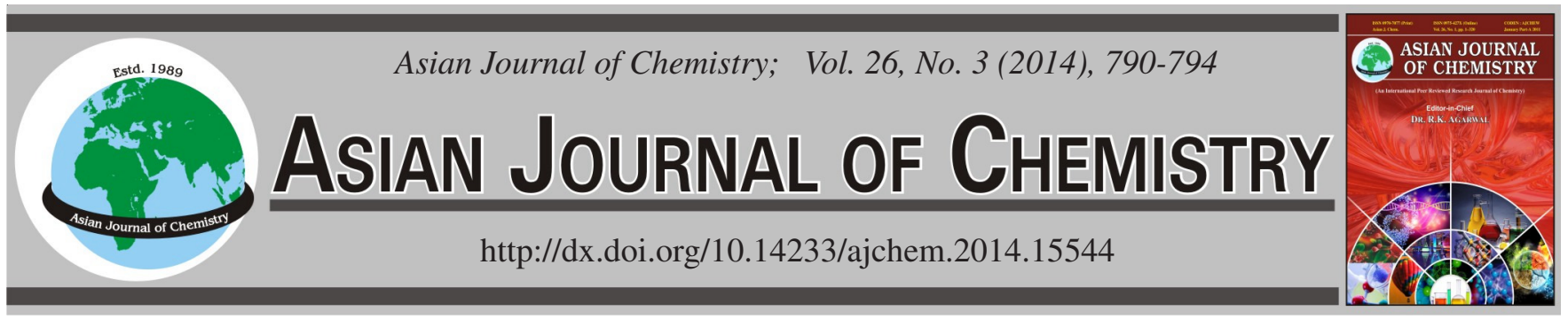

\title{
Analytical Characterization of Deteriorated Stone Surfaces from Jahangir Tomb, Lahore, Pakistan
}

\author{
S. Gulzar ${ }^{1, *}$, M.N. Chaudhry ${ }^{1}$, J.P. Burg ${ }^{2}$ and S.A. SAEED ${ }^{3}$
}

${ }^{1}$ College of Earth and Environmental Science, University of the Punjab, Lahore-54590, Pakistan

${ }^{2}$ Geological Institute, Swiss Federal Institute of Technology, Zurich, CH-8092, Switzerland

${ }^{3}$ Sohail Saeed and Associates, Lahore-54590, Pakistan

*Corresponding author: Fax: +92 42 35831866, Tel: +92 300 9422811; E-mail: saimagulzar@yahoo.com

\begin{abstract}
The paper describes severe deterioration throughout the historic structures in the Jahangir Tomb in Lahore (Pakistan) and specifically its richly decorated facades. The visually identified and megascopically studied deteriorated stone surfaces were sampled from the historic structures and analyzed with advanced chemical techniques including XRF, SEM-EDS in addition to the basic data generated by conventional methods. The results showed the presence of mainly sulphate minerals (gypsum: $\mathrm{CaSO}_{4} \cdot 2 \mathrm{H}_{2} \mathrm{O}$, anhydrite: $\mathrm{CaSO}_{4}$ and thenardite: $\mathrm{Na}_{2} \mathrm{SO}_{4}$ ), calcium oxalate with a high content of clay particles mainly illite. In addition we found a considerable content in nitrate $\left(\mathrm{NO}_{3}{ }^{-}\right)$and chloride $\left(\mathrm{Cl}^{-}\right)$. An extensive network of fissures was found on surfaces directly exposed to rainwater. Furthermore, massive colonization by lichen was also found to affect the exterior facades of carved stone by strongly adhering to the substrate: this is clearly observed in $\mathrm{XRD}$ and scanning electron microscopic examination. The presence of all these deterioration products and factors demonstrate the action of hybrid atmospheric conditions combined with the surrounding polluted environment.
\end{abstract}

Keywords: Stone, Weathering, Jahangir Tomb, Pakistan.

\section{INTRODUCTION}

Historic buildings/monuments represent an important part of our world's cultural heritage. The alarming increase of weathering damage due to environmental pollution agents (natural and anthropogenic) on cultural heritage and the danger of irretrievable loss of cultural heritage has resulted in great efforts worldwide for their conservation and preservation $^{1-3}$. Currently, Pakistan is facing problems/challenges in the field of built heritage conservation due to lack of scientific research and analysis of the historic materials for their appropriate conservation ${ }^{4,5}$.

The Jahangir Tomb represents the distinctive Mughal architecture of $17^{\text {th }}$ century with intricate decorative details. It is losing its historic fabric due to the ongoing and accelerating deterioration as shown in Fig. 1. The deterioration facade of the historic structures is due mainly to the attack of atmospheric pollutants emitted, by increasing traffic and industry as well as unfavorable climatic patterns. These produced different types of deleterious deterioration products like cracks, deformations, crusts along with the complete material loss at some locations.

Different samples (fragments) collected from the sound and deteriorated surfaces were subjected to a detailed analytical investigation ${ }^{6-8}$. One of the main objectives of this study was to identify the causes and processes of deterioration along with the deterioration products and to understand their complex relationship. Their characterization was based on ICOMOSISCS $^{9}$ to start developing the weathering forms index for the stone heritage structures in Lahore, Pakistan.

\section{EXPERIMENTAL}

The samples were collected from interior as well as exterior exposed surfaces of the stones to study the deterioration products and their damage patterns ${ }^{10,11}$. The sampling locations were identified first (Fig. 1) and then studied megascopically in order to include the various deteriorated surfaces with different deterioration patterns. After that, small fragments of stones were also collected from sound parts (inner cores) to determine the original composition of the stone as well as from the deteriorated stone fabric (Table-1) for complete and comparative analysis.

Mineralogy of the original stone and deteriorated fragments was determined with X-ray diffraction using Bruker, AXS D8 Advance powder diffractometer with $\mathrm{Cu} \mathrm{K}_{\alpha}$ radiation. The diffractograms were obtained with a Lynxeye super speed detector, step scanning from $5^{\circ}$ to $80^{\circ}$. 


\begin{tabular}{|c|c|c|c|c|c|}
\hline \multicolumn{6}{|c|}{$\begin{array}{l}\text { TABLE-1 } \\
\text { SAMPLED SANDSTONE FRAGMENTS DESCRIPTION OF COLOUR, TEXTURE, MINERALOGY, AND ANALYTICAL } \\
\text { TECHNIQUE WITH DETERIORATION CHARACTERIZATION BASED ON ICOMOS WEATHERING FORM INDEX }\end{array}$} \\
\hline Sample & Colour and texture & $\begin{array}{l}\text { Megascopic } \\
\text { identification }\end{array}$ & Mineralogical composition & $\begin{array}{l}\text { Analytical } \\
\text { technique }\end{array}$ & $\begin{array}{l}\text { Deterioration } \\
\text { characterization }\end{array}$ \\
\hline DSF-1b & Reddish and Cracks & Cracks & $\begin{array}{l}\text { Quartz, Alkai-Feldspar, Hematite, Clay } \\
\text { traces }\end{array}$ & $\begin{array}{l}\text { Petrography, } \\
\text { SEM/EDS }\end{array}$ & Craquele \\
\hline DSF-2b & Light Red and Flaky & Detachment & $\begin{array}{l}\text { Quartz, Alkai-Feldspar, Hematite, Clay } \\
\text { traces, Gypsum traces }\end{array}$ & $\begin{array}{l}\text { Petrography, } \\
\text { XRD }\end{array}$ & $\begin{array}{l}\text { Blistering and } \\
\text { Exfoliation }\end{array}$ \\
\hline DSF-3 & $\begin{array}{l}\text { Brown Red and } \\
\text { Perforated }\end{array}$ & Material Loss & $\begin{array}{l}\text { Quartz, Alkai-Feldspar, Gypsum, Anhydrite, } \\
\text { Hematite, Clay }\end{array}$ & $\begin{array}{l}\text { XRF, } \\
\text { Petrography, XRD }\end{array}$ & Alveolization \\
\hline DSF-4 & $\begin{array}{l}\text { Yellow Spoty and } \\
\text { Flaky }\end{array}$ & Discolouration & $\begin{array}{l}\text { Quartz, Alkai-Feldspar, Gypsum, Anhydrite, } \\
\text { Hematite traces, Clay, Halite }\end{array}$ & $\begin{array}{l}\text { XRF, XRD, } \\
\text { Petrography, } \\
\text { SEM/EDS }\end{array}$ & $\begin{array}{l}\text { Bleaching, Chromatic } \\
\text { Alteration }\end{array}$ \\
\hline DSF-5 & White\& Rough, Pitted & Deposition & $\begin{array}{l}\text { Quartz, Alkai-Feldspar, Gypsum, Thenardite } \\
\text { Hematite traces, Clay rich particles }\end{array}$ & $\begin{array}{l}\text { XRF, XRD, } \\
\text { SEM/EDS }\end{array}$ & Efflorescence \\
\hline DSF-6 & $\begin{array}{l}\text { Black and Rough } \\
\text { Eroded }\end{array}$ & Pollution & $\begin{array}{l}\text { Quartz, Alkai-Feldspar, Gypsum, Thenardite } \\
\text { Hematite traces, Clay rich particles }\end{array}$ & XRD, SEM/EDS & Crust \\
\hline DSF-7 & $\begin{array}{l}\text { Greenish Brown and } \\
\text { Perforated }\end{array}$ & $\begin{array}{l}\text { Biological } \\
\text { Colonization }\end{array}$ & $\begin{array}{l}\text { Quartz, Thenardite traces, Hematite traces, } \\
\text { weddelite, whewellite, Clay rich particles }\end{array}$ & $\begin{array}{l}\text { Petrographic, } \\
\text { XRD, SEM/EDS }\end{array}$ & Lichen Growth \\
\hline $\begin{array}{l}\text { DSF-1a } \\
\text { and } \\
\text { DSF-2a }\end{array}$ & Original stone & $\begin{array}{l}\text { Without } \\
\text { deterioration\& } \\
\text { sound } \\
\text { fragments }\end{array}$ & $\begin{array}{l}\text { Quartz, Alkai-Feldspar, Hematite, Clay } \\
\text { traces }\end{array}$ & $\begin{array}{l}\text { Petrographic, } \\
\text { Chemical }\end{array}$ & Without deterioration \\
\hline
\end{tabular}
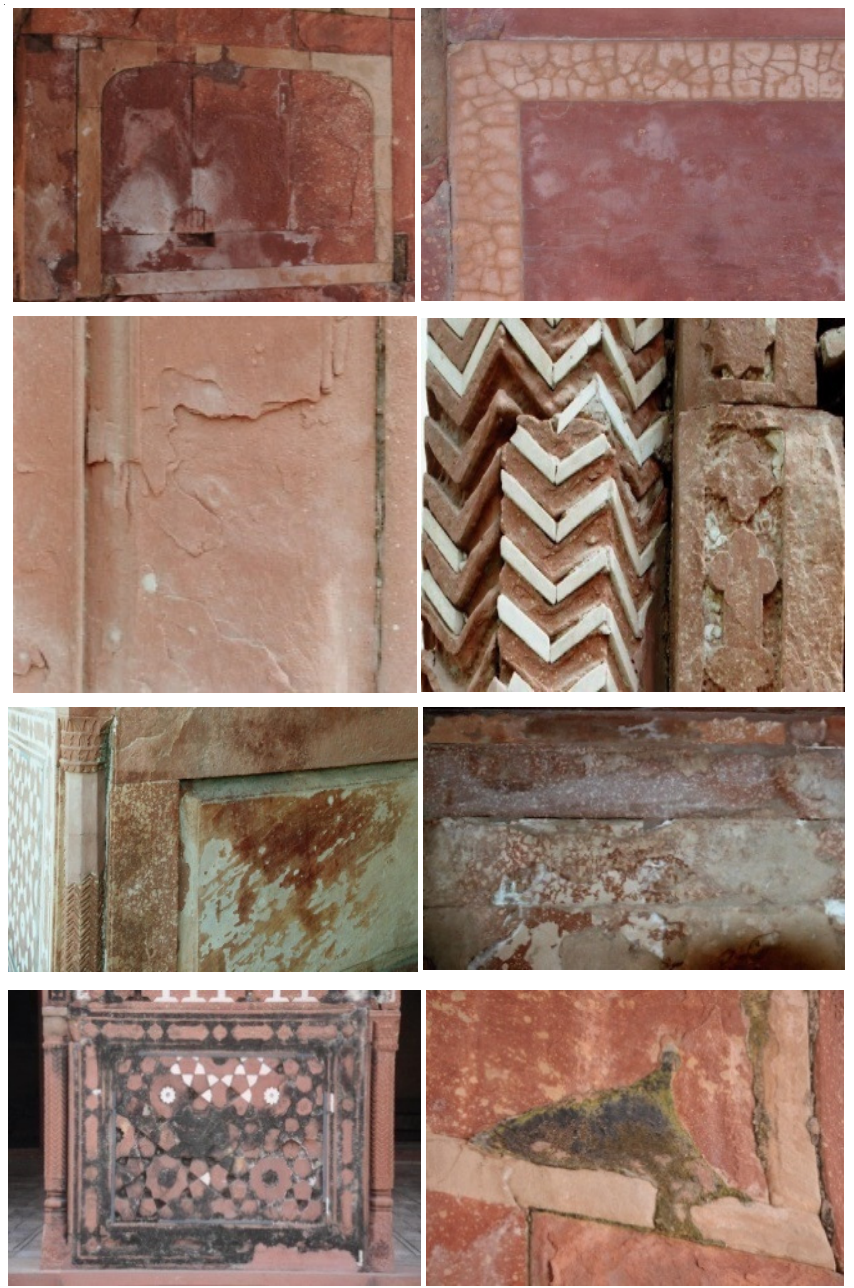

Fig. 1. Historic Deteriorated Stone Surfaces; a) cracks and fractured stone b) network of cracks c) detachment of layers or flaky stone surface d) eroded surface with materials constituent loss e) leaching of Fe constituents or staining with yellowish fragile crust formation $\mathrm{f}$ ) white crusts (gypsum) and white-coloured deposition g) black crusts and $\mathrm{h}$ ) fresh greenish biological colonization
The XRF results were obtained on fused glass beads by using wave-length dispersive $\mathrm{X}$-ray fluorescence spectrometer (WD-XRF, Axios, PAN alytical) equipped with 5 diffraction crystals for 10 major $\left(\mathrm{SiO}_{2}, \mathrm{TiO}_{2}, \mathrm{Al}_{2} \mathrm{O}_{3}, \mathrm{Fe}_{2} \mathrm{O}_{3}, \mathrm{MnO}, \mathrm{MgO}\right.$, $\left.\mathrm{CaO}, \mathrm{Na}_{2} \mathrm{O}, \mathrm{K}_{2} \mathrm{O}, \mathrm{P}_{2} \mathrm{O}_{5}\right)$ and 21 trace elements $(\mathrm{S}, \mathrm{Sc}, \mathrm{V}, \mathrm{Cr}$, $\mathrm{Co}, \mathrm{Ni}, \mathrm{Cu}, \mathrm{Zn}, \mathrm{Ga}, \mathrm{Rb}, \mathrm{Sr}, \mathrm{Y}, \mathrm{Zr}, \mathrm{Nb}, \mathrm{Ba}, \mathrm{La}, \mathrm{Ce}, \mathrm{Nd}, \mathrm{Pb}$, Th, U). In addition, thin and cross-sections from the collected fragments were prepared for observations under scanning electron microscope (SEM, JEOL JSM-6390LA with energy dispersive X-ray analyzer EDS) to further confirm the deterioration products morphology and constituting elements. The conventional standard chemical analysis was used for the qualitative and quantitative evaluation of the soluble salt content in the samples to further elaborate XRD results.

\section{RESULTS AND DISCUSSION}

Petrographic examination: Examination of thin sections under petrographic polarizing optical microscope further established the difference between the original stone constituents and the deterioration products that developed afterwards. The fresh sandstone (Fig. 2a) showed mainly subangular to subrounded quartz grains and feldspar with hematite imparting the red hue of the stone $\mathrm{e}^{12}$. On the other hand the deteriorated stone fragments (Fig. 2b) presented the distorted/edge corroded quartz grains (Fig. $2 \mathrm{c}$ ) and rusty/altered feldspar resulting into exfoliation/pitting, characteristics of natural deterioration (Fig. 2d) with dark brown clustered particles in patches (Fig. 2e) corresponding to secondary deposition of organic content $\mathrm{t}^{12,13}$.

Chemical analysis: The XRF measurements performed on samples (Table-2) clearly indicated the deviation of the deteriorated fragments (DSF-1b, 4, 5, 6 and 7) contents from the sound stone sample DSF-1a collected from the un-weathered stone. The chemical analysis indicated that the stone is mainly composed of silica with appreciable amounts of $\mathrm{Al}_{2} \mathrm{O}_{3}$, $\mathrm{Fe}_{2} \mathrm{O}_{3}$ and low amounts of transition metal oxides. The increased 
TABLE-2

CHEMICAL COMPOSITION OF SAMPLES DETERMINED BY XRF ANALYSIS (\%)

\begin{tabular}{ccccccc}
\hline Sample & DSF-1a & DSF-1b & DSF-4 & DSF-5 & DSF-6 & DSF-7 \\
\hline $\mathrm{SiO}_{2}$ & 87.105 & 82.815 & 88.7 & 92.397 & 90.979 & 92.011 \\
$\mathrm{TiO}_{2}$ & 0.148 & 0.113 & 0.12 & 0.168 & 0.159 & 0.112 \\
$\mathrm{Al}_{2} \mathrm{O}_{3}$ & 5.606 & 7.713 & 3.116 & 2.21 & 2.559 & 2.1 \\
$\mathrm{Fe}_{2} \mathrm{O}_{3}$ & 2.11 & 2.97 & 3.99 & 1.05 & 07 & 2.01 \\
$\mathrm{FeO}$ & 0 & 0 & 0 & 0 & 0 & 0 \\
$\mathrm{MnO}$ & 0.022 & 0.051 & 0.021 & 0.019 & 0.029 & 0.022 \\
$\mathrm{MgO}$ & 0.163 & 0.149 & 0.163 & 0.119 & 0.091 & 0.161 \\
$\mathrm{CaO}$ & 0.247 & 0.99 & 0.129 & 0.53 & 0.097 & 0.009 \\
$\mathrm{Na} \mathrm{O}_{2}$ & 0.189 & 0.203 & 0.149 & 0.199 & 0.117 & 0.161 \\
$\mathrm{~K}_{2} \mathrm{O}$ & 3.01 & 3.13 & 2.2 & 2.071 & 2.834 & 2.027 \\
$\mathrm{P}_{2} \mathrm{O}_{5}$ & 0.02 & 0.02 & 0.05 & 0.019 & 0.02 & 0.019 \\
$\mathrm{Cr}_{2} \mathrm{O}_{3}$ & 0.037 & 0.017 & 0.011 & 0.041 & 0.037 & 0.016 \\
$\mathrm{NiO}$ & 0.009 & 0.006 & 0.005 & 0.007 & 0.009 & 0.002 \\
$\mathrm{H}_{2} \mathrm{O}$ & 0 & 0 & 0 & 0 & 0 & 0 \\
$\mathrm{CO}_{2}$ & 0 & 0 & 0 & 0 & 0 & 0 \\
$\mathrm{LOI}$ & 0.553 & 0.919 & 1.05 & 1.17 & 1.099 & 1.35 \\
\hline $\mathrm{Total}$ & 99.219 & 99.096 & 99.704 & 100 & & 100 \\
\hline
\end{tabular}

TABLE-3

ION CONCENTRATION OF SOLUBLE SALTS IN SAMPLES (\%)

\begin{tabular}{|c|c|c|c|c|c|c|c|}
\hline Sample Fragment & $\mathrm{Na}^{+}$ & $\mathrm{K}^{+}$ & $\mathrm{Mg}^{+2}$ & $\mathrm{Ca}^{+2}$ & $\mathrm{NO}_{3}^{-1}$ & $\mathrm{SO}_{4}^{+2}$ & $\mathrm{Cl}^{-1}$ \\
\hline DSF-1a & .002 & .017 & 0.44 & 0.88 & 0 & 0 & 0 \\
\hline DSF-1b & .0019 & .027 & 0.45 & 0.98 & 0.75 & 0.09 & 0.94 \\
\hline DSF-3 & .027 & .019 & 0.29 & 1.01 & 0.75 & 0.21 & 1.36 \\
\hline DSF-5 & .002 & .031 & 0.44 & 1.22 & 0.9 & 0.98 & 1.83 \\
\hline DSF-6 & .029 & 0.051 & 0.39 & 1.01 & 1.1 & 0.87 & 1.42 \\
\hline DSF-7 & .022 & 0.049 & 0.41 & 0.89 & 3 & 1.2 & 1.36 \\
\hline
\end{tabular}

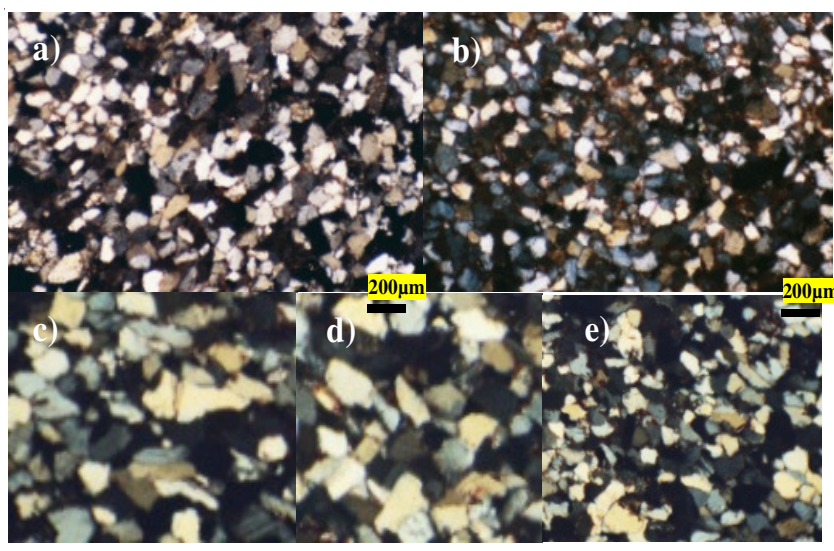

Fig. 2. Optical microscope images of the sandstones $(4 \times 10$ cross nichols $)$; a) general view of a sandstone sample without deterioration and high concentration of quartz with accessory minerals b) deteriorated sandstone with rusted boundaries and cracked fragmented grains of quartz and organic patches c) distorted quartz grains d) rusted boundaries and alteration of minerals and e) patches of organic matter

amount of alumina in DSF-1b is associated with its wind transported clay particles ${ }^{13}$. DSF-4 with exceptionally high $\mathrm{Fe}$ content is responsible for its yellowish incrustation on red sandstone surface and may be attributed to the enhanced dissolution and oxidation of Fe-bearing compounds ${ }^{10}$. The high amounts of silica and increased LOI (loss of ignition) in samples DSF5 and DSF-6 indicated where newly formed soluble salts were washed-out by rain water and created deposition of atmospheric dust ${ }^{8,13}$, which makes stone surface fragile. Sample DSF-
7 with the highest LOI (loss of ignition) confirmed the high organic content (lichen colonized stone substrate) readily seen through petrographic examination. As regards the amounts of soluble salts on samples collected from deteriorated surfaces, sulphates are the most abundant ions in comparison to chlorides and nitrates (exceptionally high for DSF-7), together with $\mathrm{K}^{+}$, $\mathrm{Na}^{+}, \mathrm{Mg}^{+2}$ (Table-3). The absence of anionic contents on sound stone sample (collected from the inner core) clearly indicated that the soluble salts belong to the deterioration rather than to solubilized constituent of heritage materials.

$\mathrm{X}$-Ray diffraction analysis and scanning electron microscopy: XRD analysis further complemented the chemical analysis (Table-2 and 3) and Fig. 3a and b. The deteriorated sandstones revealed the presence of quartz (high peaks), with medium peaks for feldspar, gypsum, anhydrite and thenardite $\left(\mathrm{Na}_{2} \mathrm{SO}_{4}\right)$ in addition to regular interval peaks for clay/ illite attributed to the wind transported deposition on eroded stone surfaces. Halite traces were also found in few samples (DSF4 and DSF-5).

Under the SEM-EDS calcium sulphate crystals were detected in the deteriorated fragments (Fig. 4a) but not in their perfect morphology. The XRD pattern (Fig. 3b) showed gypsum and anhydrite peaks, both consisting of $\mathrm{Ca}$ and $\mathrm{S}$ but they were indistinguishable under EDS elemental analysis. The second type of sulphate is platy crystals of sodium sulphate (Fig. 4b) which was established by XRD to be thenardite $\left(\mathrm{Na}_{2} \mathrm{SO}_{4}\right)$. Glauberite $\left[\mathrm{Na}_{2} \mathrm{Ca}\left(\mathrm{SO}_{4}\right)_{2}\right]$ crystals (Fig. $\left.4 \mathrm{c}\right)$ are found rarely ${ }^{7,8}$. The order of abundance of sulphate minerals, from SEM observations and based on XRD analysis is: 

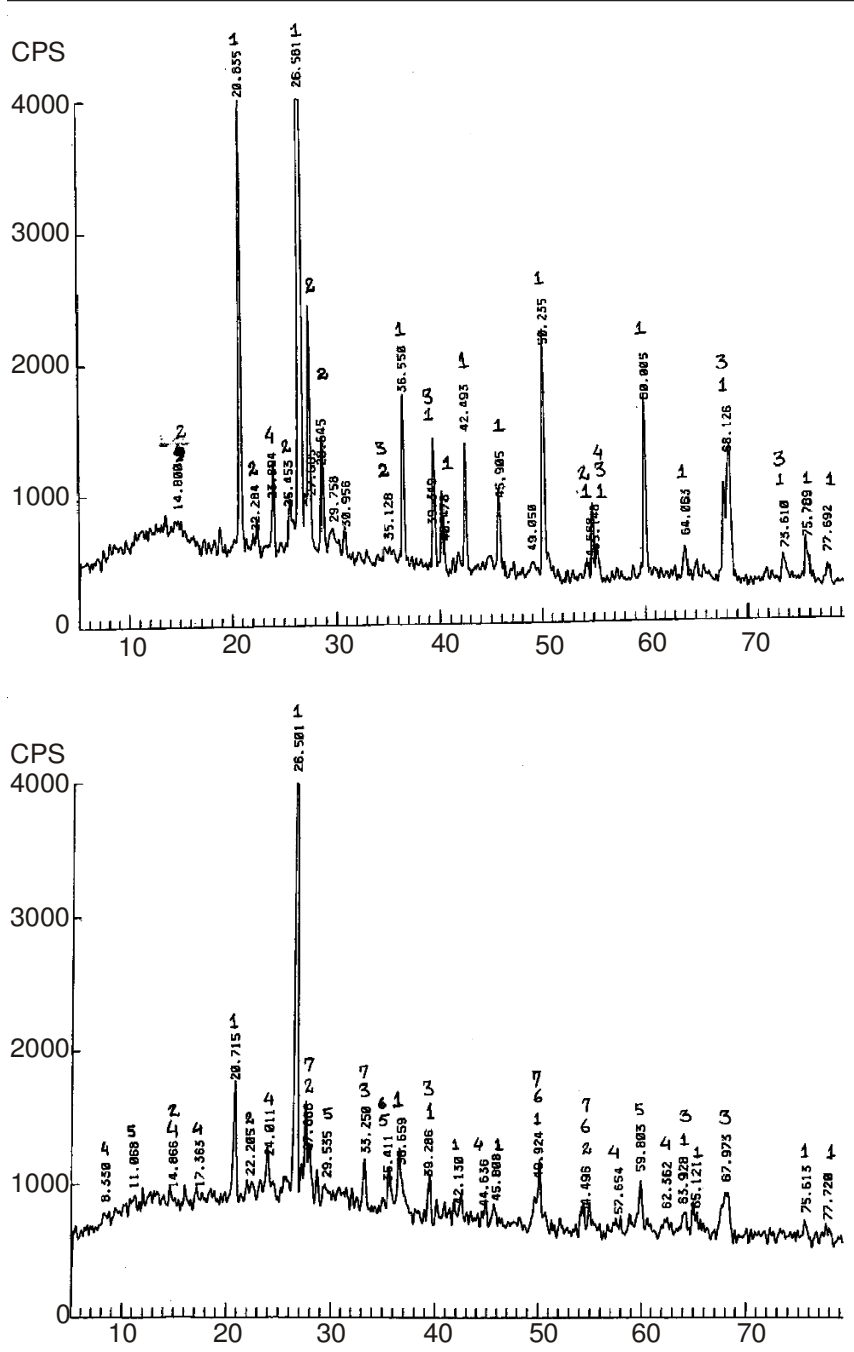

Fig. 3. XRD diffractogram of sandstone; a) original core fragment b) deteriorated fabric fragment. 1. quartz; 2. alkali feldspar; 3. hematite; 4. illite/ clay; 5 . gypsum; 6. anhydrite; 7. thenardite; 8 . weddelite/ whewelite

\section{$\mathrm{CaSO}_{4} \cdot 2 \mathrm{H}_{2} \mathrm{O}>\mathrm{CaSO}_{4}>\mathrm{Na}_{2} \mathrm{SO}_{4}>\mathrm{Na}_{2} \mathrm{Ca}\left(\mathrm{SO}_{4}\right)_{2}$ Gypsum Anhydrite Thenardite Glauberite}

The other interesting observation was the presence of clay particles networks (Fig. 4d) on the stone substrate (DSF-6 and DSF-7) which can be attributed to the second generation product derived from the atmospheric pollutants or wind driven deposi$\operatorname{tion}^{3,10}$. The region with black and green discolouration (under stereomicroscope Fig. 2c) is composed of fibrils and granular masses (Fig. 4d) under the SEM enveloped with a network of clay-rich particles. The presence of calcium oxalate (traces of whewelite, weddellite) in DSF-7 further confirmed biochemical deterioration due to lichens ${ }^{14}$.

Mechanisms for the deterioration products: The chemical, mineralogical and textural characterization of deterioration products in the examined stone samples suggested the development of various weathering patterns at the same time/ location due to the interaction between stone and its surrounding environment which is being altered by both natural and anthropogenic causes ${ }^{15}$.

The studied Jahangir Tomb (Shahdara-Lahore) is situated in NE Pakistan. The climatic pattern showed extremely high temperatures in summers from $40-48^{\circ} \mathrm{C}$ during May and June

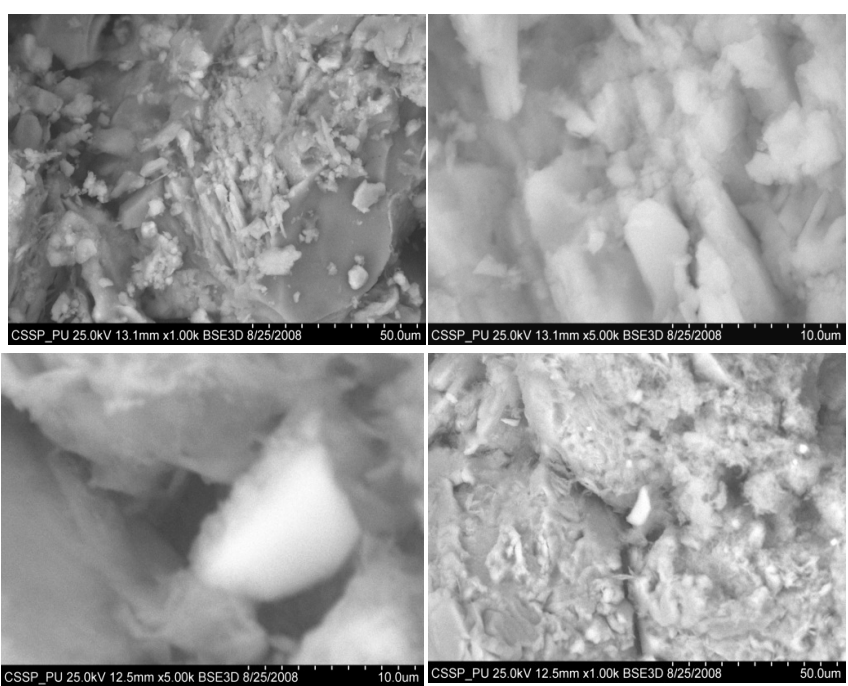

Fig. 4. SEM photomicrographs of the deteriorated sandstone; a) platy calcium sulphate crystals surrounded by clay minerals b) thenardite crystals c) glauberite crystals and d) microorganisms growth; 1 . Fibrillar structures and 2. granular masses

followed by the monsoon season from end June to mid of September with heavy rain falls. The humidity increases to almost $70 \%$ with the arrival of monsoon and the climate remains hot and humid till the end of September. After the monsoon, climate becomes again warm and dry during October and November with average temperature around 30 ${ }^{\circ} \mathrm{C}$ with rains and generated extreme dryness and haziness that normally captures pollutants. The winter months starting from December account for cool, pleasant and sunny day with a cold night pattern ${ }^{4,5}$. Significant growth of urban population (approximately 10 million) in Lahore resulted into the development of small and large scale industries in the suburbs (like studied Shahdara area) with an increase of vehicular traffic by ten times during the last decade. This contributes to major amounts of sulphur-bearing compounds into the atmosphere. Environmental pollution being the key factor for deterioration of the Jahangir Tomb, it is presently acting in its hybrid formation consisting of natural (temperature, humidity, rain, microorganisms) and anthropogenically (SOx, NOx, particulate matter) originated factors sharing the same deterioration scenario with the world heritage site of Taj Mahal in India ${ }^{16,17}$.

\section{The analytically characterized sandstone deterioration} patterns are

Cracks: The cracks in the historic fabric are one of the typical deterioration pattern that develops naturally through the process of aging ${ }^{16,17}$ but the extensive cracked surfaces of the Jahangir tomb (Fig. 1a and b) highlighted the contribution of other weathering phenomena (natural as well as anthropogenic) that mainly include internal stresses developed within the stone by interacting foreign particles (soluble salts, pollutants deposition, rain water/ humidity etc.). That usually reduces the stone strength and the rock becomes more susceptible to other deterioration forms.

Exfoliation: The sandstone exfoliation 18 is the most common deterioration phenomenon observed in the Jahangir Tomb (Fig. 1c) due to salt crystallization. It is mainly formation of gypsum in result of wetting drying cycles and is attributed 
to S-rich environmental conditions. The oxidation (reaction of major pollutant $\mathrm{SO}_{2}$ with the stone substrate) and substitution (dissolution of calcite which in turn forms gypsum crystals and their growth with drying process) of sulphate products including gypsum-CaSO${ }_{4} \cdot 2 \mathrm{H}_{2} \mathrm{O}$, anhydrite- $\mathrm{CaSO}_{4}$ and thenardite- $\mathrm{Na}_{2} \mathrm{SO}_{4}$ exerts mechanical pressures on stone and is the root cause of stone disruption into observed flakes and blisters $^{18}$.

Alveolization: The observed alveolization in the Jahangir tomb (Fig. 1d) which results from ongoing deterioration processes, is referred to the formation of interlinked cavities that allow deposition of foreign materials (clay, pollutants, salts, etc.). These depositions react with the substrate constituents and generate heterogeneities in physical and chemical properties of the stone substrate causing either material loss or cavity formation.

Bleaching: The dissolution and oxidation of Fe-containing constituents in sandstone (one of the common chemical weathering) in the Jahangir tomb (Fig. 1e) produced the deposition of yellowish iron oxide in the form of stains and crust everywhere on the structures.

Efflorescence: The pictorial survey and visual analysis of this historic site (Fig. 1f) indicated various locations with efflorescence. The analytical investigation also showed that these white-coloured powdery surfaces making crystallized salt crusts on sandstone are made of soluble thenardite and halite salts and are loosely bound to the stone substrate ${ }^{19}$.

Crust: The black crust formation in the Jahangir Tomb's structures (Fig. 1g) is mainly attributed to the polluted urban environment and is analytically proved by the presence of gypsum and associated products ${ }^{18}$.

Lichens colonization: The presence of biological colonization indicated the biochemical deterioration of the sandstones which is mainly attributed to lichens in this case (Fig. 1h). The high humidity during Monsoon season and high emission levels of nitrogen oxides due to increased vehicular traffic in the area favoured the generation of lichens ${ }^{14}$.

\section{Conclusion}

The presented analytical investigation of deteriorated stone samples from the Jahangir tomb in Shahdara-Lahore shows that deterioration is mainly due to the polluted environment further enhanced by the natural phenomena. Its extent is strongly dependent on the surface exposition to the environment. The major atmospheric pollutant- $\mathrm{SO}_{2}$ played a vital role in the formation of black and white crusts on the stone surface. These crusts resulted in the consolidation of hydratable salts and loosening of the packing constituents, thus creating zones of weakness, which were exfoliated. This study confirms that salt crystallization causes both severe damage and weathering in addition to the transformation (alterations-bleaching) of stone surfaces by the deposition of airborne polluted particles either on exposed or sheltered areas.

Volume changes due to the formation of the deterioration products like gypsum, thenardite, halite and nitrates compounds in combination with climatic patterns (high humidity, rains and frequent haziness) have accelerated the process of sandstone cracking, blistering, staining as well as bleaching, whereas increase in nitrogen pollutants and transition metal oxides content has generally enhanced the whole process of environmental attack on these historic structures by contributing in catalytic oxidation of atmospheric gaseous $\mathrm{SO}_{2}$ and to the sulphation of stone substrate.

On the other hand, city climatic conditions, cumulative attack by other natural agents, biological activity in addition to the atmospheric pollution have played dominant roles in weakening the historic materials and creating zones of black and green patinas, causing loss of aesthetic beauty to this historic monument.

According to these new results, an appropriate conservation plan will be developed. This will include cleaning and consolidation, in order to identify the most suitable materials and methodologies to remove lichens and the deterioration products while avoiding the loss of original substrate and ensuring an increased cohesion to deteriorated stones.

\section{ACKNOWLEDGEMENTS}

The authors would like to thank the College of Earth and Environmental Sciences, University of the Punjab-Lahore (Pakistan) and the Department of Earth Sciences of the Swiss Federal Institute of Technology, ETH-Zurich (Switzerland) for their collaboration in conducting this research.

\section{REFERENCES}

1. K.L. Gauri and G.C. Holdren, Environ. Sci. Technol. 15, 386 (1981).

2. F. Delalieux, C.P. Cardell, V. Todorov, V. Dekov and R. Van Grieken, J. Cult. Herit. 2, 43 (2001).

3. Z. Qin, J. Zhang and X.Y. Peng, Geogr. Res., 24, 928 (2005).

4. S. Gulzar, M.Sc Thesis, Environmental effects on cultural heritage: Shahdara Complex-Lahore, University of the Punjab, Lahore, p. 6280 (2004).

5. S. Gulzar, M.N. Chaudhry and J.P. Burg, Asian J. Chem., 25, 8484 (2013).

6. W.F. Cole, A. Wilson and C.J. Lancucki, J. Aust. Ceram. Soc., 11, 7 (1975).

7. S.Z. Lewin and A.E. Charola, SEM, 1, 695 (1978).

8. S.L. Sarkar, S. Chandra and M. Rodhe, Mater. Struct., 25, 429 (1992).

9. V. Verges-Belmin, Illustrated glossary on stone deterioration patterns ICOMOS-ISCS, ICOMOS France (2008).

10. F.G. Xu, J. Tang and S.H. Gao, Environ. Pollut. Control, 12, 36 (2008).

11. L. Binda, M. Lualdi and A. Saisi, Int. J. Archit. Herit., 1, 380 (2007).

12. M.S. Khan, M. Ahmad and M.A. Khan, Lahore Museum Bull., 13, 115 (2000).

13. S. Siegesmund, R. Snethlage and J. Ruedrich, Environ. Geosci., 56, 451 (2008).

14. C. Vazquez-Calvo, M. Buergo and R. Fort, Mater. Charact., 58, 1119 (2007).

15. R. Norvaisiene, R. Miniotaite and V. Stankevicius, Mater. Sci., 9, 102 (2003).

16. B.M. Feilden and P. Beckmann, The Taj Mahal, Agra, Uttar Pradesh, India', (International Centre for the Study of the Preservation and Restoration of Cultural Property, Rome) (1987).

17. M.Y. Awan, Pak. J. Eng. Appl. Sci., 3, 8 (2008).

18. F.G. Xu, J. Tang J and S.H. Gao, J. Cult. Herit., 11, 15 (2010).

19. A.E. Charola and R. Ware, in eds: S. Siegesmund, T. Weiss and A. Vollbrecht, Acid deposition and the deterioration of stone: A brief review of a broad topic. In Natural Stone, Weathering Phenomena, Conservation Strategies and Case Studies, Geological Society Special Publication 205, London: Geological Society of London, pp. 393-406 (2002). 